\title{
TITLE:
}

\section{Relationship between balance and cognitive performance in older people}

\section{AUTHORS}

Massimo Leandri. School of Medicine, DINOGMI and CIND, University of Genova. Via Dodecaneso 35, 16146 Genova, Italy

Jackie Campbell, School of Health, The University of Northampton, Boughton Green Road, Northampton, NN2 7AL, UK

Luigi Molfetta, School of Medicine, DINOGMI, University of Genova, L.go Daneo, 3, 16132 Genova, Italy

Cristina Barbera, School of Medicine, University of Genova, Via L.B. Alberti 4, 16132 Genova, Italy

Massimo Tabaton, School of Medicine, DIMI, Via L.B. Alberti, 4, 16132 Genova, Italy

Corresponding author: Massimo Leandri, CIND, Via Dodecaneso 35, 16146 Genova, Italy. Tel. +39-010-3537081

Fax +39-010-3538565

e-mail: massimo.leandri@unige.it.

\section{RUNNING TITLE}

Balance and cognitive impairment 


\section{SUMMARY}

We investigated the relationship between balance and cognitive level in a group of 70 women with no definite AD or MCI diagnosis and no impairment of daily activity. Static stabilometry and MoCA test were performed. The antero-posterior sway component was demonstrated to be the best predictor of the MoCA overall score. As visual and proprioceptive components of balance could safely be excluded in our assessments, the vestibular system is to be considered as a putative link between balance and cognitive impairment.

\section{KEYWORDS}

Postural Balance

Aging

Cognitive performance

Vestibular system 


\section{INTRODUCTION}

Progressive balance and cognitive impairment are a physiological consequence of age [1,2], but there is great variability among individuals as to the extent of these phenomena. The question arises whether impairment in balance may be associated with cognitive decline or could be considered a suitable predictor of the latter[3]. Instrumental analysis of balance has demonstrated a significant impairment in Alzheimer's disease (AD) and mild cognitive impairment (MCI) compared to age matched normals, implicating damage to the vestibular pathways as the most probable cause[4]. There might therefore be an association between balance measures and cognitive performance, even in a population of older people with no definite AD or MCI diagnosis, no complaint of memory loss, and without impairment of daily activity. Therefore, this study investigates the relationship between balance and cognitive level in physically healthy older subjects, living independently, in the absence of a cognition-related diagnosis.

\section{MATERIALS AND METHODS}

A sample of 70 women was investigated. Women only were selected for this study because the higher risk of falls in women $[5,6]$ and previous evidence of sex differences in balance measures [7]. They were following a program of physical activity at a local gymnasium, and had no impairment of daily activity, nor orthopedic, otolaryngoiatric, neurologic or cardiovascular conditions. Mild hypertension was not considered an exclusion criterion. Their age ranged between 41 and 93 years $($ mean $=73 ; s d=9$ years $)$.

The Italian version of the MoCA test [8] was administered, with adjustment for education . No other neuropsychological tests were administered in order to keep the procedure as simple as possible.

A static platform (Balance by VertigoMed, Italy) was used to perform stabilometry. The participants' balance was tested on a firm surface and with interposition of a 30mm thick rubber 
foam mat. The two conditions of open and closed eyes were tested. Each of the 4 measurement sessions lasted $42 \mathrm{~s}$. Among the various possible stabilometry parameters, we choose to analyse the antero-posterior and medio-lateral sway (total length of the sway path in the AP and ML directions), as these are considered most reliable among the various proposed measurements [1,9]. Because we wanted to exclude the visual component of balance, only sway measures with eyes closed are considered in this paper. The possible effect of age on the balance measures was also included in the analyses. All procedures were part of physical and cognitive screening routinely performed at the gymnasium; subjects gave their informed consent to data collection and handling.

\section{RESULTS}

The analysis for this work focused on relationships between sway measures and cognitive ability as measured by the total corrected MoCA score.

Forty subjects (57\%) had total adjusted MoCA scores within the normal range $(>=26)$. The median MoCA score for this group was 28. Thirty (43\%) had scores below 26 (median score $=24$, minimum $=19)$. The median total adjusted MoCA score of all participants was 26 (IQR=24-28).

In order to assess whether any of the sway measures were associated with the MoCA score, a multiple linear regression model was constructed using a forced entry procedure (using IBM SPPS v22). Checks for multicollinearity, biases due to undue influence of individual cases, homoscedasticity and normality of residuals were performed and were all satisfactory.

Table I shows the regression model slope coefficients in the eyes closed condition and it can be seen that only the AP sway on a firm surface was a significant predictor of the corrected total MoCa score. A linear regression model with only this predictor gave an $\mathrm{R}^{2}$ value $=0.172$, indicating that $17 \%$ of the variance in MoCA scores could be accounted for by the AP sway, eyes closed measure alone. The adjusted $\mathrm{R}^{2}$ for this one-predictor model was 0.160 , which is suggesting that this only 
drops to $16 \%$ when generalising to a population of which this sample was representative. Although AP sway (eyes closed) by itself accounts for less than a fifth of the total variation in cognition as measured by the MoCA, it does show a positive association and is likely to make a significant improvement in any existing risk model for cognitive impairment.

Although none of the participants had any functional signs of dementia or MCI, the sample could be divided into two groups: those with MoCA scores $\geq 26$ and those with scores $<26$, where 26 is generally taken to be the lower limit for normal cognition. As the MoCA scores are not normally distributed, an independent-samples median test was used to compare the AP sway, eyes closed values between the two groups. There was a statistically significant difference (test statistic $=14.933 ; \mathrm{df}=1 ; \mathrm{p}<0.001)$ between the groups, with the group with lower MoCA score having greater sway (normal MoCA score group, median $=157.00 \mathrm{~mm}, \mathrm{IQR}=135.25-203.75 \mathrm{~mm}$; group with $\mathrm{MoCA}<26$, median $=256.00 \mathrm{~mm}, \mathrm{IQR}=185.50-379.25 \mathrm{~mm}$ ). It can also be seen that the AP sway measure in the lower MoCA score group is more variable than in the normal score group.

\section{DISCUSSION}

A short foreword may be necessary as to the choice of subjects. The aim of our study was to investigate a possible assciation between cognitive performance and balance in a population of older individuals who had no impairment of daily living activities (hence the clinical diagnosis of AD could be ruled out). It is worth stressing that we were not looking for a relationship between diagnostic category and balance, but level of cognition as measured by the total corrected MoCA score, in its most common form. A score of $<26$ may be an indication of MCI, but intentionally none of the participants had undergone specific neuropsychological testing for such a diagnosis. 
Analysis of our data shows that the total length of the AP sway path, measured with closed eyes, is a significant predictor of the overall score of the MoCA test and differentiates between those with normal and below normal MoCA scores. Using the closed eye condition excluded the visual component of balance. The two other systems conveying information to maintain balance are the somatosensory (proprioceptive and plantar exteroceptive) and the vestibular systems. Our subjects had no obvious somatosensory impairment, and were physically active. It is therefore likely that the association between the AP sway (eyes closed) measure and total MoCA score is indicative of vestibular impairment in those with lower MoCa scores, in agreement with the findings in AD and MCI patients and with the hypothesis that the vestibular system is functionally linked to the hippocampus in memory performance [4].

\section{ACKNOWLEDGMENTS INCLUDING SOURCES OF SUPPORT}

The study has been supported by institutional funds and equipment of CIND and DINOGMI, University of Genova. The stabilometric platform Balance was on loan by Vertigomed (Genova, Italy). The technical assistance of Dr. Eng. Carlo Tacchino, from VertigoMed, is also gratefully acknowledged.

\section{REFERENCES}

[1] Abrahamova D, Hlavacka F (2008) Age-related changes of human balance during quiet stance. Physiol Res 57, 957-964.

[2] Deary IJ, Corley J, Gow AJ, Harris SE, Houlihan LM, Marioni RE, Penke L, Rafnsson SB, Starr JM (2009) Age-associated cognitive decline. Br Med Bull 92, 135-152.

[3] Deary IJ, Whalley LJ, Batty GD, Starr JM (2006) Physical fitness and lifetime cognitive change. Neurology 67, 1195-1200.

[4] Leandri M, Cammisuli S, Cammarata S, Baratto L, Campbell J, Simonini M, Tabaton M (2009) Balance features in Alzheimer's disease and amnestic mild cognitive impairment. $J$ Alzheimers Dis 16, 113-120. 
[5] Scheffer AC, Schuurmans MJ, van Dijk N, van der Hooft T, de Rooij SE (2008) Fear of falling: measurement strategy, prevalence, risk factors and consequences among older persons. Age Ageing 37, 19-24.

[6] Ambrose AF, Paul G, Hausdorff JM (2013) Risk factors for falls among older adults: a review of the literature. Maturitas 75, 51-61.

[7] Mignardot JB, Beauchet O, Annweiler C, Cornu C, Deschamps T (2014) Postural sway, falls, and cognitive status: a cross-sectional study among older adults. J Alzheimers Dis 41, 431-439.

[8] Nasreddine ZS, Phillips NA, Bedirian V, Charbonneau S, Whitehead V, Collin I, Cummings JL, Chertkow H (2005) The Montreal Cognitive Assessment, MoCA: a brief screening tool for mild cognitive impairment. J Am Geriatr Soc 53, 695-699. Italian translation by Pirani A, Tulipani C, Neri M. 626 July 2006. www.mocatest.org.

[9] Piirtola M, Era P (2006) Force platform measurements as predictors of falls among older people - a review. Gerontology 52, 1-16. 


\section{FIGURES and FIGURE LEGENDS}

Figure 1: Box and whisker plot for AP sway (eyes closed, firm surface)(mm) for groups having MoCA scores of $<26$ and $\geq 26$

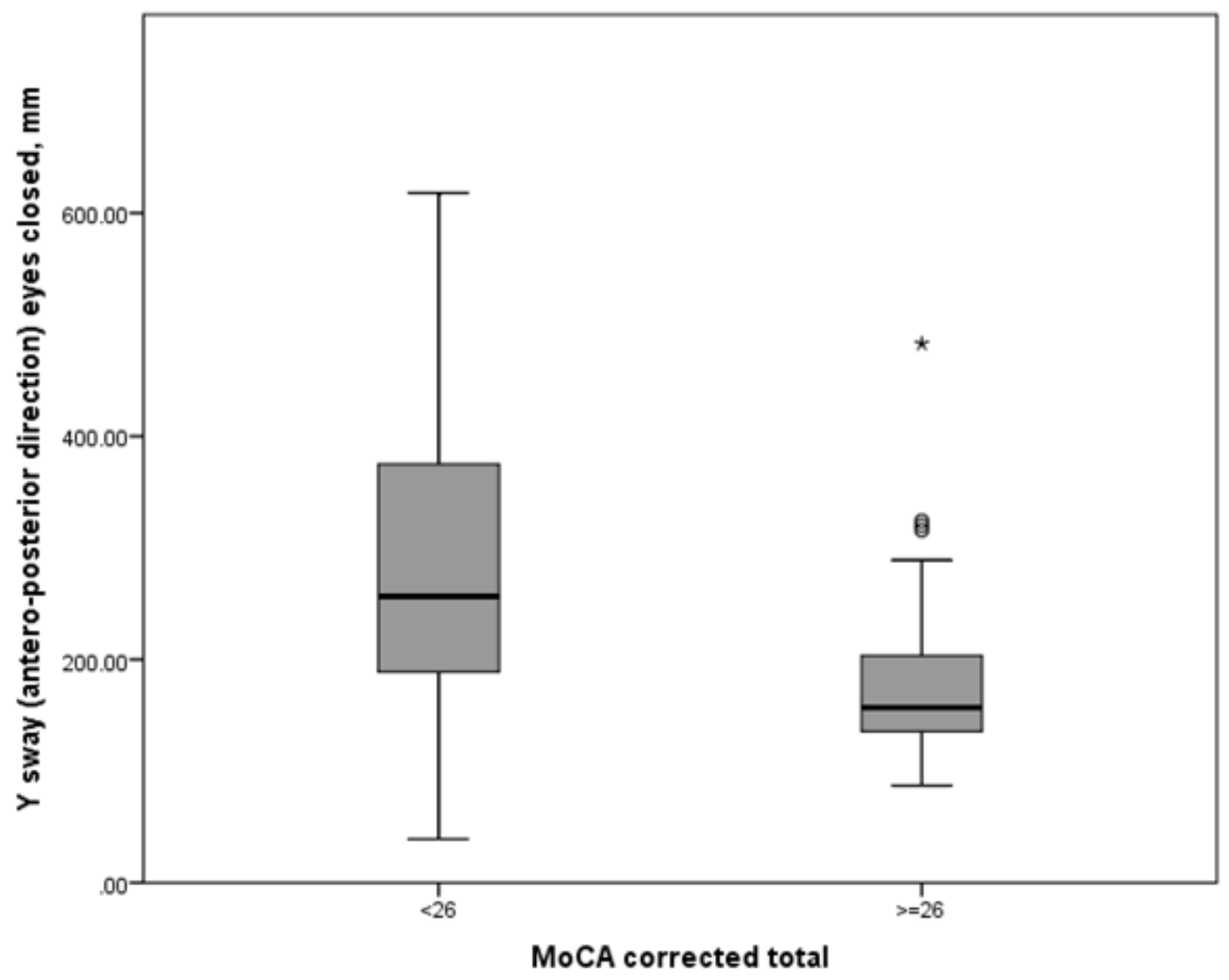




\section{TABLES}

\section{Table I Multiple regression. Outcome - total adjusted MoCA score}

\begin{tabular}{|c|c|c|c|c|}
\hline Model & \multicolumn{2}{|c|}{$\begin{array}{l}\text { Unstandardised } \\
\text { coefficients }\end{array}$} & \multirow[t]{2}{*}{$\mathbf{t}$} & \multirow[t]{2}{*}{$\mathbf{p}$} \\
\hline & $\beta$ & s.e. & & \\
\hline Age & -0.038 & 0.038 & -0.988 & 0.327 \\
\hline $\begin{array}{l}\text { ML sway, firm surface, } \\
\text { eyes closed }\end{array}$ & 0.013 & 0.007 & 1.837 & 0.071 \\
\hline $\begin{array}{l}\text { AP sway, firm surface, eyes } \\
\text { closed }\end{array}$ & -0.011 & 0.004 & -2.618 & $0.011^{*}$ \\
\hline $\begin{array}{l}\text { ML sway, foam surface, } \\
\text { eyes closed }\end{array}$ & 0.000 & 0.003 & -0.142 & 0.887 \\
\hline $\begin{array}{l}\text { AP sway, foam surface, } \\
\text { eyes closed }\end{array}$ & 0.000 & 0.001 & -0.143 & 0.887 \\
\hline
\end{tabular}

Model coefficients for multiple regression. The column labelled $\beta$ shows the estimated value of the slope of the regression line for that variable, s.e. is the standard error of the slope value, $t$ is the value of the test-statistic of a t-test comparing the slope to zero and $\mathrm{p}$ is the probability associated with the t-value. ${ }^{*}$ denotes that the slope for the predictor variable was statistically significant $(\mathrm{p}<0.05)$ 